\title{
Mapping Research Trends in Residential Construction Retrofitting: A Scientometric Literature Review
}

\author{
Mehdi Amirkhani ${ }^{1,2, *(\mathbb{D})}$, Igor Martek ${ }^{1}$ and Mark B. Luther ${ }^{1} \mathbb{D}$ \\ 1 School of Architecture and Built Environment, Deakin University, Geelong, VIC 3220, Australia; \\ igor.martek@deakin.edu.au (I.M.); mark.luther@deakin.edu.au (M.B.L.) \\ 2 Abian Design Studio, Melbourne, VIC 3031, Australia \\ * Correspondence: m.amirkhani@deakin.edu.au or mehdi@abiandesign.com.au
}

check for updates

Citation: Amirkhani, M.; Martek, I.; Luther, M.B. Mapping Research Trends in Residential Construction Retrofitting: A Scientometric Literature Review. Energies 2021, 14, 6106. https://doi.org/10.3390/ en14196106

Academic Editor: F. Pacheco Torgal

Received: 23 August 2021

Accepted: 22 September 2021

Published: 25 September 2021

Publisher's Note: MDPI stays neutral with regard to jurisdictional claims in published maps and institutional affiliations.

Copyright: (C) 2021 by the authors. Licensee MDPI, Basel, Switzerland. This article is an open access article distributed under the terms and conditions of the Creative Commons Attribution (CC BY) license (https:/ / creativecommons.org/licenses/by/ $4.0 /)$.

\begin{abstract}
The world is looking to reduce carbon emissions, prevent global warming, and become more energy sustainable. Despite the various strategies for mitigating climate change, the fact remains that $80 \%$ of greenhouse gas emissions are attributable to activities associated with the built environment, and this is where a concentrated focus is needed. Moreover, most buildings are residential, not commercial or industrial. In essence, ways must be found to reduce energy consumption and $\mathrm{CO}_{2}$ emissions from existing houses and apartments globally if sustainability is to be realised. The recognised way to achieve this is through the retrofitting of existing residential buildings. Studies in this area have increased in recent times, but the extent of the work remains unmapped and undescribed. If further progress is to be made in this field, researchers' knowledge domain so far must be documented. This literature review delivers that goal. A scientometric evaluation of research on residential retrofitting is here presented. VOSviewer, Gephi, and CiteSpace are the software packages used. Findings identify retrofitting as an emerging theme, taking off only as recently as 2017. The breadth of research is very limited, primarily concerned with calibrating trade-offs between energy costs and thermal comfort. Emerging and new opportunities to expand retrofitting research are identified. Finally, while several journals accommodate publications on this topic, analysis reveals Energy and Buildings to be the significant citation source.
\end{abstract}

Keywords: residential construction; retrofitting; sustainable construction; literature review; research trends; scientometric review

\section{Introduction}

The earth is warming, and this is generally attributed to human activity. Greenhouse gases are identified as the principal culprit, with $\mathrm{CO}_{2}$ being the primary greenhouse gas. $\mathrm{CO}_{2}$ is emitted as a by-product from the burning of fossil fuels. For the most part, fossil fuels are associated with vehicle transportation, car, train and aeroplane use [1]. However, the built environment is the most significant energy consumer, both in terms of initial building and ongoing maintenance. The manufacture of building materials-such as bricks and timber-consumes as much as $10 \%$ of the total energy produced [2]. Additionally, buildings last a long time and require vast amounts of energy to operate and maintain. Keeping the lights on and air-conditioners running in buildings consume over $50 \%$ of the world's energy output. More dramatic still, $80 \%$ of all greenhouse gas emissions are directly attributable to activities associated with the urban environment. If that were not enough, buildings deplete resources at rapacious levels. A total of $15 \%$ of global water resources go into building construction, such as in making concrete. Buildings consume $25 \%$ of world timber stocks, 30\% of all other natural resources, and $40 \%$ of human-made materials. Moreover, $50 \%$ of all the waste dumped into landfills come from building demolition. The impact of buildings on the built environment is nothing short of devastating [3].

Of course, none of this has gone unnoticed. Significant initiatives to fight 'global warming' and roll back greenhouse gas emissions have been pursued worldwide. The 
Paris Climate Accord is perhaps the best known, with almost all major developed and many developing countries 'promising' to cut back on fossil-based energy use. Australia, for example, has committed to reducing its $\mathrm{CO}_{2}$ output to $28 \%$ of its 2005 levels by 2030. [4]. This is a considerable reduction, and if it is to have any chance of being realised, it clearly must target the built environment. To that end, governments around the world have sponsored building rating tools. The idea is to assess aspects of a building that impact energy use, consolidate these assessments, and deliver a rating. A higher '5-star' rating, in this scheme, signifies that a building is a better energy performer than, say, a ' 3 star' rated building. The primary rating tools are the Building Research Establishment Assessment Method (BREAM), established in 1990 in the UK and regarded as the first. Leadership in Energy and Environmental Design (LEED) emerged in 1998 as the US answer to BREAM. Green Star appeared in 2003 as a BREAM adaption for Australian conditions [5-7]. There are, in fact, as many as 600 energy rating instruments worldwide [8,9]. Each rating tool assesses different aspects of a building's energy performance and weighs them differently. The variations are arguably necessary to reflect the different building and environmental conditions, but it begs the question as to whether these tools deliver a reliable or objective measure given that different tools deliver different findings. There are further problems. One that stands out is that the ratings are typically predictive, rating a building off-plan rather than measuring actual performance. Indeed, when actual performance is measured, results have been shown to differ from predictions. Despite the marketing claims that they have penetrated the built environment market, these tools have had limited impact. Generally, they are used by prominent building owners who wish to showcase their social conscience. For example, in Australia, only $0.5 \%$ of the Australian building industry has sought a rating from Green Star [10]. We also know that in as many as 50\% of these cases, the motivation for seeking an energy rating was indeed to highlight ownership of a 'trophy sustainability icon' [11].

Nevertheless, there is a bigger problem again. The problem is that most of the built environment is not made up of offices, factories or public facilities, but rather residenceshouses and apartments. In many countries, dwellings make up at least $80 \%$ of the built environment [12]. Moreover, the obvious fact remains that most building stock is not recent, but stock that already exists. The bulk of buildings were built before the 1980s before any energy efficiency guidelines or regulations were introduced. [5] This all points to a pivotal yet neglected priority in construction sustainability research. The clear stand-out candidate demanding attention in this regard is residential retrofitting. By far, the biggest category of buildings to be found strewn across the urban landscape are houses-places where people live. Although building new buildings more sustainably is undoubtedly laudable, the existing building stock also needs attention. Indeed, finding ways to refurbish existing residential buildings sustainably may be the single most crucial quest before the construction community today. Added to this, we have to date no comprehensive assessment of the state of research regarding the retrofitting of residential builds. This paper addresses that need.

\section{Literature Review}

Building retrofitting is the key to reducing a buildings energy consumption while at the same time improving indoor environmental quality and minimising harmful emissions. It refers to the post-occupancy modification of thermal elements (walls, roofs and floors), services (heating, ventilation, air-conditioning, lighting, and water services), as well as fittings (windows and doors). Various terms are used in reference to building retrofitting, including refurbishment, renovation, retro-commission, and tune-up. Building refurbishments generally consider aesthetics and tenant amenities. However, they can also involve upgrades to the building systems in ways that potentially enhance building performance. Although renovation is similar to refurbishment, with the terms sometimes used interchangeably, renovation is more closely associated with buildings. Retro-commissioning is the process of regularly testing and adjusting building systems on a three to five-year cycle to 
ensure appropriate functional performance. Tune-up is a generic term that encompasses existing buildings systems or aspects of retro-commissioning and retrofit.

Research suggests that using appropriate environmental technologies in buildings can reduce energy consumption between $35 \%$ and $80 \%$ [13]. For example, Hughes and Shonder [14] report retrofitting 4003 homes at Fort Polk, Louisiana, by switching natural gas into a ground source heat pump for water and space heating, cutting energy usage by one third. A subsequent study demonstrated a 35\% reduction in house energy usage by simply using modest insulation upgrades and air sealing [15]. A comprehensive retrofit of two apartment buildings in Basel, Switzerland, slashed heating requirements (hot water, ambient heating, and ventilation) by 100\%, making the buildings effectively zero thermal energy houses [16]. Francisco, Palmiter [17] argue that sealing ductwork alone can reduce houses' annual heating and air-conditioning energy usage by $15 \%$ to $20 \%$. Voss [18] investigated the impact of retrofitting 14 residential building projects by adding solar design concepts, including solar collectors to preheat domestic hot water (DHW) while also supplementing indoor heating demand, enclosing balconies with openable glass elements, and adding solar wall-heating with transparent insulation. The projects returned energy savings of up to $70 \%$. A study in North China revealed that retrofitting a multi-story residential building could diminish energy usage by about $50 \%$ while still providing an acceptable indoor thermal environment [19]. Though energy reduction of as much as $70-85 \%$ is possible in residential buildings through retrofitting, the investment can be very high [20]. Variable user behaviour along with building management can also significantly impact the energy savings of buildings [21]. Studies have shown that counterproductive user interventions in design conditions can nullify predicted energy savings by up to $75 \%[22,23]$.

It is estimated that building energy usage will increase over 2005 levels by as much as $150 \%$ by 2050 and rise further to $220 \%$ by 2095 [24]. Globally, China ranks second in building energy consumption and first in regard to residential buildings [25]. Residential buildings in the European Union (EU) are responsible for more than $25 \%$ of the total energy usage in the region [26]. Due to the high energy conservation potential, investing in building retrofitting has become a major global priority. Studies in the EU predict that retrofitting residential buildings would reduce energy usage by 78\% [27]. In Russia, $60 \%$ of apartment buildings need extensive retrofitting [28]. In Melbourne, Australia, the number of buildings that have undergone retrofitting work has grown over the last few years, with the upgrading of lighting and HVAC systems being among the most common retrofit activities [29]. The replacement of a broken service proves to be the most significant motivator for retrofitting. According to Shah [30], retrofitting can be undertaken at several levels, including light, medium, extensive, or comprehensive retrofitting, as well as through demolition. Zou, Stewart [31] also divide retrofitting into three levels: existing building commissioning, standard retrofitting, and deep retrofitting. Existing building commissioning can be achieved with low risk and capital outlay by enhancing building operation and maintenance procedures. The first level of retrofitting can deliver energy reduction of up to $25 \%$. Standard retrofitting replaces existing services to enhanced energy performance, improving performance by up to $45 \%$. Deep retrofitting is the integration of whole building improvements, leading to energy savings of over $45 \%$. The US Green Building Council (USGBC) defines major or deep retrofitting as renovating HVAC elements, major envelope alterations, and significant internal rehabilitation [30]. Similarly, the Building Research Establishment (BRE) defines a major retrofitting as those results in the provision, extension or modification of thermal elements or building services [30]. The building's performance condition determines the level of retrofitting.

Surveys conducted in European countries as diverse as Bulgaria, Poland, and Portugal reveal that homeowners are primarily motivated to invest in environmental retrofitting technologies that improve energy usage and comfort [32]. Specifically, the most common information sought by homeowners engaged in retrofitting were expected benefits in terms of reduced heating bills and associated technical information needed to avoid mistakes. 
Retrofitting buildings can involve substantial costs and a complex decision-making process requiring various stakeholders, including landlords, tenants, property managers, developers, architects, energy consultants, and local councils. However, these stakeholders are generally privy to different knowledge and technical information and respond dissimilarly in the retrofitting process. For example, most consultants use more complicated tools than regular architects would use. It is relevant to note that architects approach design holistically based on their experiential knowledge and are not primarily focused on improving buildings' energy performance. Overall, barriers such as the complexity of retrofits and financing, combined with the complications of determining the efficacy of potential energy-saving strategies, may prevent retrofitting. In summary, while buildings can be expected to perform better due to retrofitting, results are heavily contingent on the approaches taken and the means by which they are applied. The best cost-benefit solutions are not widely understood or documented. Although cognizant of the potential windfalls, homeowners, landlords, and investors remain uncertain as to how to proceed. At the same time, industry practitioners tend to peddle pre-packaged solutions, while a wider appreciation as to the best, unequivocally accepted retrofitting approaches remains undescribed.

Thus, while building practitioners and stakeholders acknowledge the need to use environmental technologies in retrofitting residential buildings, there is still a lack of knowledge of the efficiency of these systems and their applications to improve residential buildings energy and comfort performance. This research explores the extent of these deficiencies. It adopts structured, quantitative methods that generate an objective, comprehensive portrait of the existing state of research knowledge in environmental technology applications in retrofitting residential buildings. This paper describes the state of play as documented by research academics regarding the environmental performance of residential buildings. The various approaches that have been undertaken are explored, including renewable energy systems, ventilation strategies, innovative conditioning systems, construction retrofits, new sensor technologies, optimised control strategies and more. This review identifies systems with high energy-saving potential along with those exhibiting high vulnerabilities. This study's outcomes may be used to inform future research directions in retrofitting residential buildings and aid funding efforts by policymakers and practitioners.

\section{Method}

This review-based study adopts a holistic approach to assess research outputs in environmental technology applications in retrofitting residential buildings, published in quality academic journals. The overall workflow of this study is shown in Figure 1 and contains five stages.

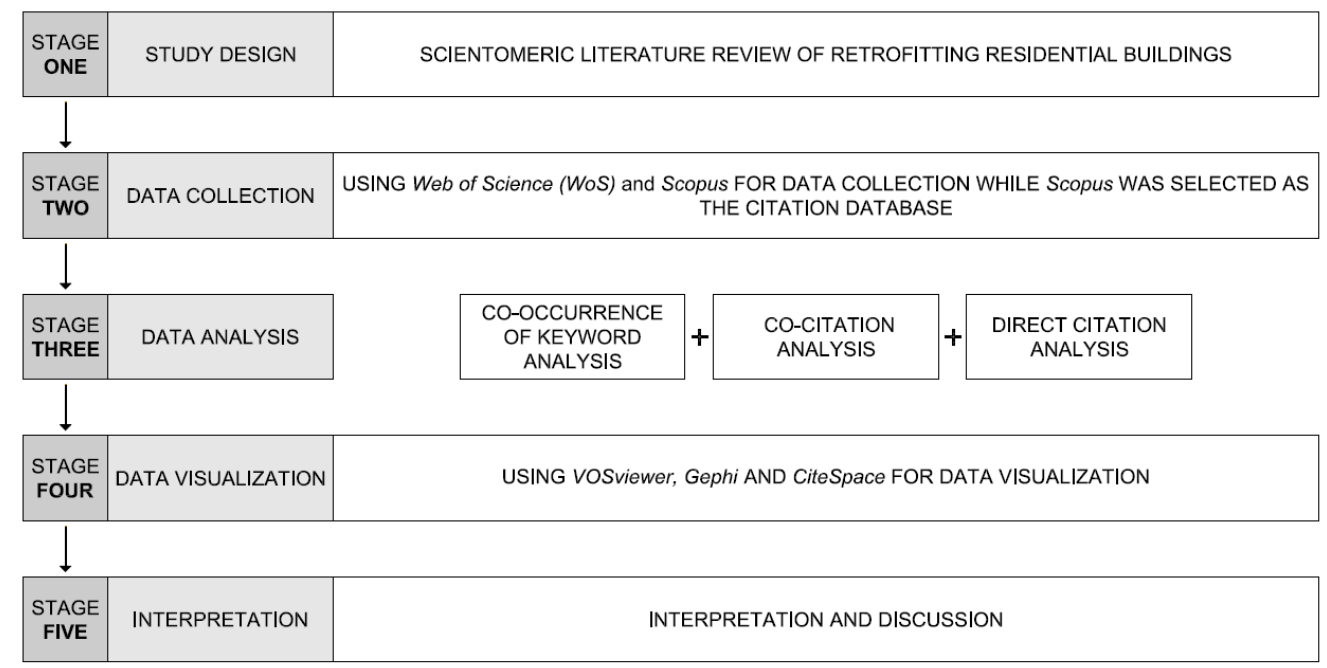

Figure 1. The research flowchart reviewing the literature on the retrofitting of residential buildings. 


\subsection{Data Collection}

Only articles published in peer-reviewed journals were considered, as these have been peer-assessed for reliability and quality. Several databases are available for science mapping, including Web of Science (WoS), Scopus, ScienceDirect, SpringerLink, ProQuest, PubMed, Google Scholar, Dimensions Microsoft Academic, Patent Derwent innovation index, BOOK Citation index, and others. Nonetheless, WoS and Scopus are the most widely used databases in science mapping due to the accepted view that they contain higher data quality. WoS has more than 21,000 peer-reviewed journals that have been indexed in the database since 1900, with almost 1.9 billion cited references from over 171 million records [33]. In 2004, Elsevier launched Scopus, which covers more than 23,500 peer-reviewed journals [34]. It has over 75 million records going back as far as 1788 across different subject areas, such as health, life, physical and social science [34]. Although most databases include authors, affiliations, abstracts, and keywords, WoS and Scopus contain further information, particularly citation data. However, Li, Goerlandt [35] argues that while both WoS and Scopus are popular within the scientific community, Scopus has surpassed WoS over the last five years. As such, this research uses the Scopus database to retrieve and download articles. The search terms were "energy/retrofitting/residential buildings", "retrofit/residential", and "retrofitting/residential". The findings were limited to peer-reviewed journal articles. The research scope includes title, abstract and keywords. The record content covers citation information, bibliographical information, abstract, keywords, and funding details. Of some 1500 articles extracted, these were reviewed manually for relevance with the title and abstracts being read for content. As a result, the overall pool of retrieved articles was reduced to 511, being deemed relevant to the study at hand. These were downloaded and the entire article set subjected to fine-grained analysis.

\subsection{Literature Review Metrics}

Scholars use variable quantitative and qualitative literature reviewing methods to understand and organise recent findings. Among these, science mapping is the approach most used. It relies on mathematical statistics and visualisation techniques to evaluate a research domain's structural aspects and research policies [36]. Science mapping illustrates the correlations between disciplines, fields, and individual publications using a spatial approach [37]. The scope of science mapping research can be research, a scientific discipline, or topic areas considering a specific research question [38]. Science mapping also has a proven history in picturing systematic patterns in large bibliographical units and comprehensive literature review bodies [36,39]. The overall workflow in a science mapping analysis incorporates several steps, including data retrieval, preprocessing, network extraction, normalisation, mapping, analysis, visualisation, as well as interpreting and generating conclusions from the results [40]. It employs three metrics, including bibliometrics, scientometrics, and informetrics [39]. However, these metrics do not have clear boundaries and are generally used interchangeably.

According to Pritchard [41], bibliometrics is "the application of mathematical and statistical methods to books and other media of communication". Bibliometrics provides objective analysis and is generally used for quantitative research evaluation of academic outputs, especially in big datasets [42,43]. It can introduce a transparent, systematic and reproducible review process according to the statistical measurement of scientific activity, science, and scientists [44]. Bibliometrics focuses predominantly on the production, distribution, dissemination, and usage of data delivered in any document (journal, book, conference, patent, or website) [45].

Nalimov and Mulchenko [46] first introduced scientometrics and defined it as "applying quantitative research methods on the development of science as an information process". In other words, scientometrics is used to study science as an economic activity or discipline [47]. It is part of the sociology of science and has application to science policymaking. Although scientometrics is indistinguishable from bibliometrics in that it deals with quantitative analysis of publications or other forms of communication [48], it also 
measures scientific productivity and utility [44]. Figure 2 illustrates the different methods used in the scientometric analysis.

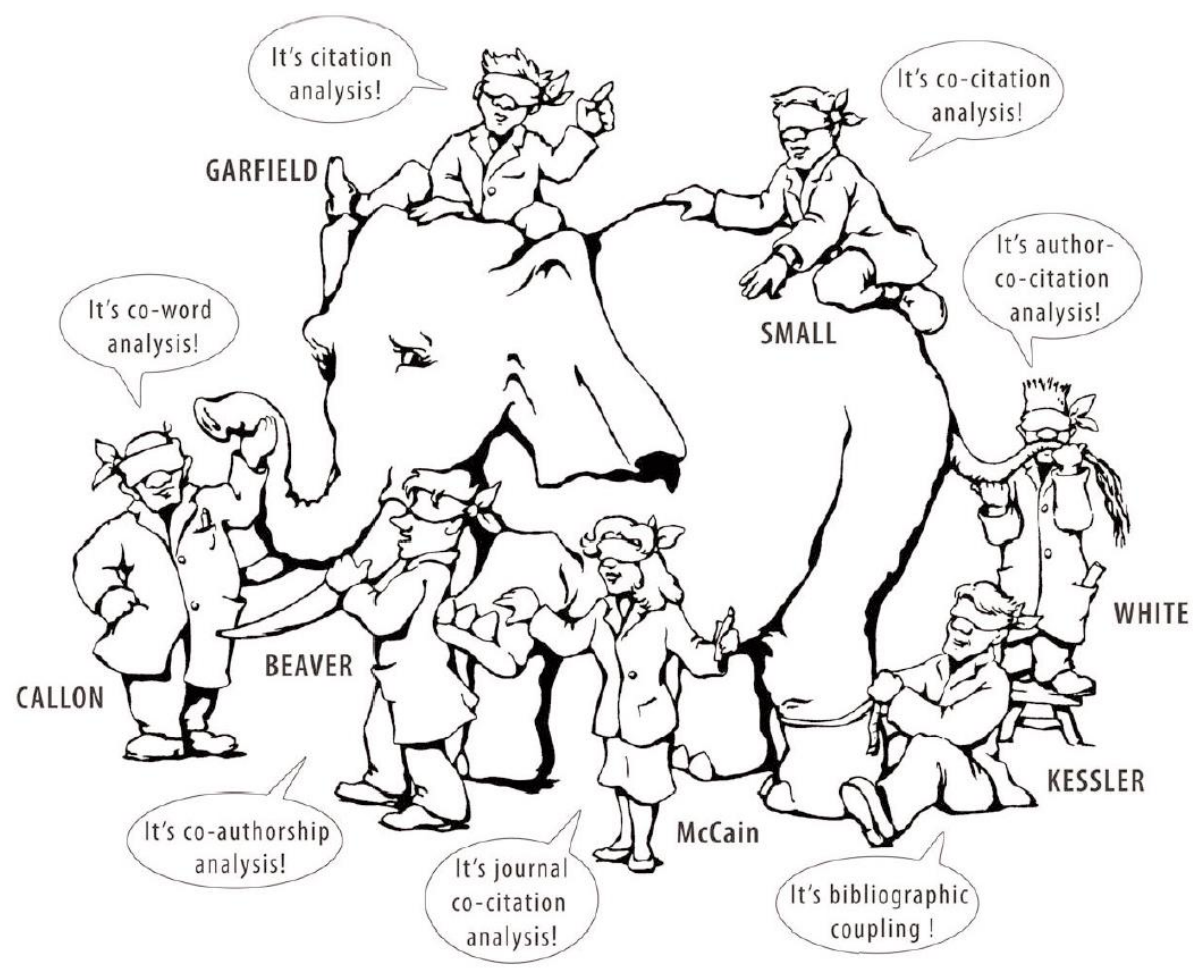

Figure 2. Methods applied in the scientometric analysis [49].

Informetrics, which come from the German term "informetrie", was first introduced by Nacke [50] and was widely accepted by the early 1990s [47]. Informetrics focuses on the discovery of mathematical models that describe the properties of information [51]. It is the study of quantitative aspects of data in any social group, not just among scientists, and in any form, not just bibliographies and records [48]. It investigates the quantitative aspects of spoken or informal communication, records, and information [48]. As such, it can be used to analyse information that lies outside the boundaries of both bibliometrics and scientometrics metrics.

The current study focuses on journal articles where the co-occurrence of keywords and document co-citation analysis was conducted, along with measurements of direct citation assessment of outlets and co-authorship. These techniques are widely accepted and recommended in construction research [52,53]. Moreover, they are also regarded as the core components of scientometric analysis, helping scholars comprehend the current research status [54]. Word co-occurrence analysis (also called co-word analysis) helps map the strength of correlation between research outlets in textual data [55]. It is based on the number of co-occurrences of two words appearing in the same outlet, abstract or keyword units. Co-word analysis can expose and visualise the interaction between research topics [56]. Here, we applied the co-word analysis concept to measure the co-occurrence of keywords specified by authors; the author keywords. Co-citation analysis is defined as two publications that are cited together in one research outlet [57]. If two publications have been regularly co-cited, they are highly correlated, and there is thus a robust semantic similarity between them. Due to co-citation analysis characteristics, many scholars use the approach to investigate the core concerns of a field [58]. The direct citation analysis (also known as a cross citation or inter-citation) illustrates the direct citing correlations between research outlets without creating connections based on a third-party paper [59]. In scientometric analysis, two authors have collaborated if they co-author papers. Coauthorship measurement has been divided into three levels, including micro-level (author 
analysis), meso level (institutes or cities analysis), and macro-level (country/regional analysis). Micro-level measurement clusters paper authors by common paper, which is used to understand who highly productive authors are in a scientific domain of inquiry and to determine teams of collaborating researchers. Likewise, meso and macro-level measurements are used to determine active contributors in a scientific domain of inquiry and how they are connected at institution, city, or country levels.

\subsection{Data Visualisation}

The visualisation technique is the most effective method for extracting data from an enormous amount of complex information and displaying them more clearly. It uses computer tools to illustrate the internal structure of information in a way that helps users develop a qualitative understanding of the data and better conduct subsequent outlier detection, pattern recognition, and much more. The visualisation technique also illustrates the correlation between data objects, the research field's development process, and the development trend. Several tools can be used for data visualisation, including VOSviewer and CiteSpace.

VOSviewer is an application used for constructing and visualising bibliometric networks at an aggregated level [60]. VOSviewer also provides a clustering function, which assigns keywords to clusters based on their co-occurrence [60]. CiteSpace is a Java application for evaluating and visualising a co-citation network [61]. This application's primary utility is to facilitate the investigation of emerging trends in a field of knowledge [62]. According to Chen [61], CiteSpace is suited for co-citation analysis. It automatically clusters collected documents and visually displays them. In the current study, both VOSviewer and CiteSpace were selected due to their suitability for extensive mapping networks and text mining capabilities.

\subsection{Technical Details of Data Analysis}

The technical details of the data analysis methodology used are as follows:

- Co-occurrence of keyword analysis: Author keywords were used to present a reproducible visualisation of the keywords using VOSviewer. A total of 1507 keywords were extracted from the dataset while fractional counting was deployed. The default minimum value of 5 was set for keyword occurrence, and a total of 51 keywords, which were connected to each other, were included in the network. The network created by VOSviewer was subsequently submitted to Gephi for further analysis.

- Co-citation analysis: This assessment was undertaken in VOSviewer. The unit of measurement was set to cite references, and the counting method was set to fractional counting. The minimum number of citations of cited papers was set to 3 . The clustering function was used in the CiteSpace application, and the labels for clusters were generated using the log-likelihood ratio (LLR) algorithm with the indexing term.

- Direct citation analysis: All references were submitted to VOSviewer for direct citation analysis while the measurement unit was sourced. The minimum value for both the number of documents of a source and the number of citations of a source was set to 10 .

- Co-authorship analysis: This measurement was undertaken in VOSviewer while the unit of analysis was set to authors and the counting method set to fractional counting. VOSviewer was used for co-authorship analysis while the unit of measurement being organisations, and the counting method was set to fractional counting. The minimum number of documents and citations of an organisation was set to 2 and 10, respectively. Additionally, co-authorship assessment was conducted with the unit of analysis being countries and the counting method set to fractional counting. The minimum number of documents of a country and the minimum number of citations were set to 10 and 15, respectively. 


\section{Results and Discussion}

A total of 511 collected articles were assessed across five parameters: published journal, co-authorship, co-occurring keywords, article citations, and regions.

\subsection{Research on Retrofitting Residential Buildings}

Research activity in the field of residential retrofitting was evaluated based on the number of publications. As it happens, Vliet [63] conducted the first study on the retrofitting of residential buildings in 1979, focusing on retrofitting apartment buildings with solar, heating, cooling and hot water. The research level and the future development trend in a particular field can be understood by plotting the quantity of literature over time and conducting multivariate measurements. Figure 3 illustrates the number of published works on the retrofitting of residential buildings between 1979 and 2021. It is apparent from this line graph that while only a few research works have been published each year to 2010 (a total of 63 research works), there has been a sudden increase in the number of published studies since that time, especially after 2017. These results suggest that there has been a recent, meaningful increase in research interest in retrofitting residential buildings and that this trend can be expected to continue.

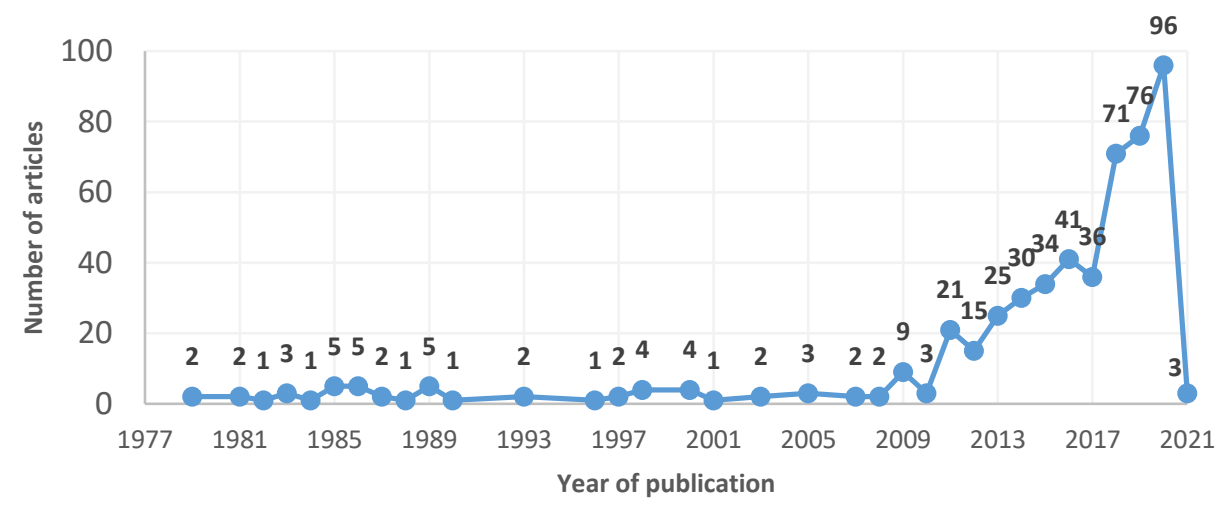

Figure 3. Yearly trend in the number of papers published on the retrofitting of residential buildings.

\subsection{Co-Occurrence of Keyword Analysis}

A co-occurrence analysis was conducted using author keywords in VOSviewer. A network of correlated keywords provides a clear understanding of scientific knowledge production in terms of relationships, patterns, and intellectual organisation of the topics covered [64]. The link strength between keywords is based on the number of documents in which both keywords occur together. Using Gephi, the following terms were merged for better analysis:

- Building retrofitting: "building retrofit", "building retrofitting", "retrofit", "retrofitting", "renovation", "refurbishment", and "optimisation".

- Energy retrofitting: "building energy retrofitting", "energy retrofitting", "energy retrofit", and "energy retrofits".

- "Residential building", "residential buildings", "residential", "residential sector", "residential building stock", "housing", "housing stock", "social housing", "buildings", and "building stock".

- "Energy-saving", "energy savings" and "energy conservation".

- "Energy efficiency measures" and "energy efficiency".

- "Energy", "energy consumption", and "energy performance".

A network comprised of 28 nodes and 145 links was generated, as shown in Figure 4, demonstrating the main areas of research identified in the field of residential retrofitting. The size of nodes illustrates its importance based on its repetition on different documents. The thickness of lines demonstrates the correlation between nodes based on the number of documents in which both occur. 


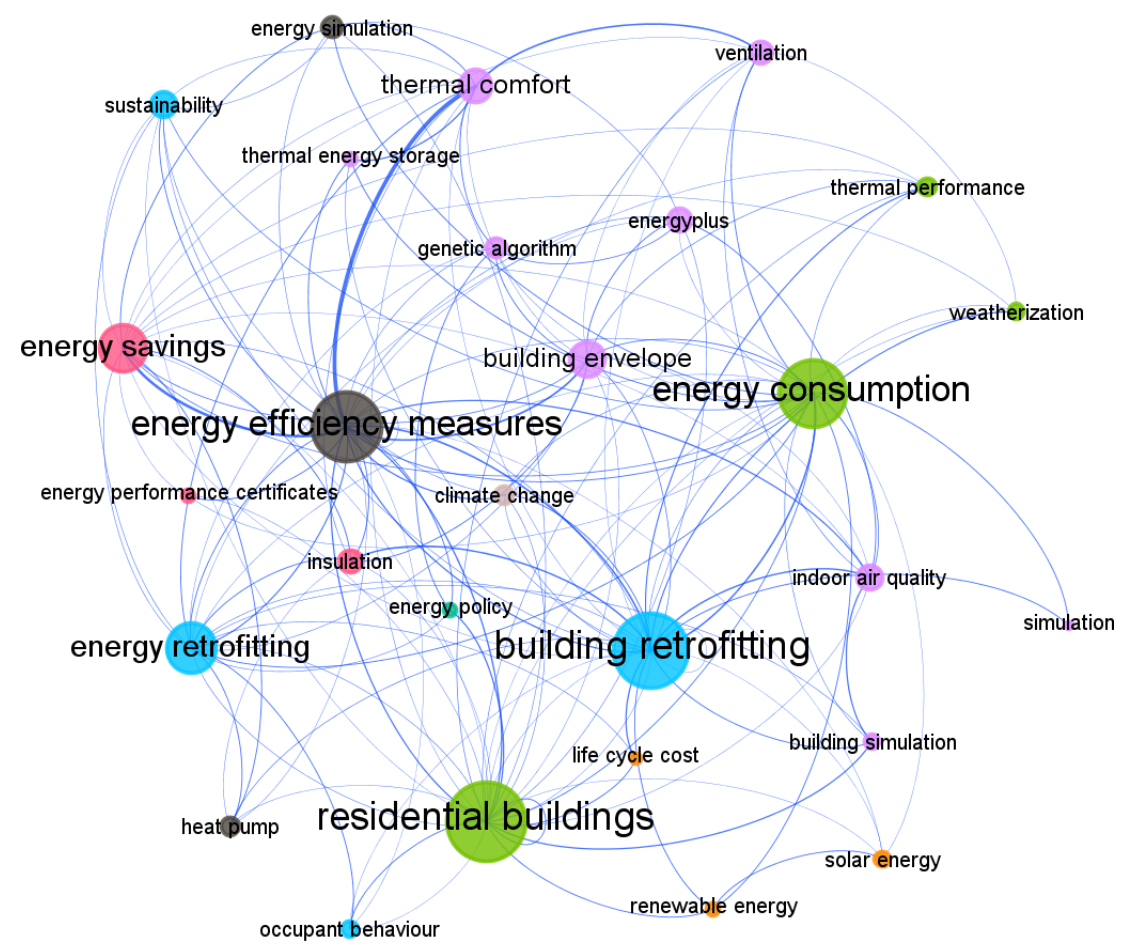

Figure 4. Main research areas in retrofitting residential buildings.

Ties between nodes can be assessed in a variety of ways when analysing network structures. Nonetheless, some measures, such as degree centrality (DC), weighted degree centrality (WDC), and relative importance, are the most widely accepted large-scale network metrics used in extracting information from a network. DC is based on a graphtheoretical network assessment approach [65]. It uses a directive and simple description of centrality and prioritises nodes in the network by counting the number of connections linked to a node. However, DC does not distinguish between the quantity and the quality of the links. Opsahl, Agneessens [66] improved DC and proposed WDC, which introduces the concept of strength, stating that the node would be more significant if it gains greater strength in the network. In other words, WDC is the sum of weighted values of the links (edges) connecting the node and its neighbours. Table 1 demonstrates the outcomes of the analysis of the network. The correlation of the research areas, as illustrated in Figure 4, and the ranking of the leading research areas, as shown in Table 1, reveal some interesting findings, reflecting gaps in the literature in the field of residential building retrofitting.

The centralising themes are 'residential buildings' and 'building retrofitting'. These themes are heavily investigated in energy, energy efficiency measures, energy consumption, and energy retrofitting. The emphasis here is primarily on 'building envelope', with the dual aims of improving 'thermal comfort' and 'energy savings'. However, residential retrofitting involves more than striking a balance between energy costs and comfort by upgrading building envelopes. Consequently, the analysis indicates that the subject of residential retrofitting is highly under-researched while at the same time revealing those areas within the domain that have attracted fledgling studies. Research themes seeded and warranting further attention include building and energy simulation, insulation, ventilation, and indoor air quality. Areas will almost no attention include energy performance certification, weatherisation, occupant behaviour, heat pumps, and perhaps surprisingly, solar energy. 
Table 1. The central focus of retrofitting residential buildings.

\begin{tabular}{|c|c|c|c|}
\hline Author Keyword & Degree Centrality & Weighted Degree Centrality & Relative Importance \\
\hline residential buildings & 31 & 19.83 & 1 \\
\hline building retrofitting & 29 & 24.08 & 2 \\
\hline thermal comfort & 12 & 13.67 & 3 \\
\hline sustainability & 9 & 4.67 & 4 \\
\hline ventilation & 8 & 5.33 & 5 \\
\hline energy efficiency measures & 27 & 32.24 & 6 \\
\hline weatherisation & 5 & 2.67 & 7 \\
\hline energy consumption & 26 & 18.25 & 9 \\
\hline thermal performance & 6 & 3.67 & 10 \\
\hline solar energy & 5 & 2.00 & 11 \\
\hline indoor air quality & 9 & 7.99 & 12 \\
\hline thermal energy storage & 4 & 4.00 & 13 \\
\hline energy savings & 18 & 10.08 & 14 \\
\hline energy retrofitting & 19 & 12.83 & 15 \\
\hline occupant behaviour & 5 & 2.75 & 16 \\
\hline genetic algorithm & 7 & 4.99 & 17 \\
\hline energyplus & 8 & 4.99 & 18 \\
\hline insulation & 8 & 6.99 & 19 \\
\hline energy simulation & 7 & 5.00 & 20 \\
\hline simulation & 2 & 2.00 & 21 \\
\hline heat pump & 6 & 3.67 & 22 \\
\hline energy performance certificates & 4 & 1.99 & 23 \\
\hline climate change & 6 & 4.5 & 24 \\
\hline energy policy & 4 & 4.00 & 25 \\
\hline renewable energy & 4 & 4.00 & 26 \\
\hline building simulation & 5 & 5.00 & 27 \\
\hline life cycle cost & 3 & 3.00 & 28 \\
\hline building envelope & 13 & 10.08 & 29 \\
\hline
\end{tabular}

\subsection{Co-Citation Analysis}

Co-citation analysis is a scientometric approach for exploring and organising core subjects and the knowledge structure in a discipline [57]. It can aggregate articles with related research content into clusters. We conducted co-citation and cluster analysis using CiteSpace to identify core factors in the retrofitting of residential buildings. The 'lookback year' for references was set to 10 years. The maximum number of links per node and the link retaining factor was set to 10 and 3, respectively. CiteScape identified 15,415 references, being $100 \%$ of the original references, as valid references. Figure 5 illustrates the co-citation analysis clusters, which consist of 711 nodes and 2307 connections. \#0 is the largest cluster with the maximum number of studies. CiteSpace automatically assigns labels to the identified clusters based on their structure rather than their content [62].

The modularity score (the symbol is $Q$ ) measures the extent to which a network can be divided into independent components (e.g., clusters) [67]. Its score ranges from 0 to 1 . A high modularity score indicates that the network components are isolated and have clear boundaries between the clusters. The modularity score (the symbol is $Q$ ) of the current study clusters is 0.3442 , showing that the boundaries between the clusters are not very clear [62].

The silhouette metric is useful in approximating the hesitation involved in identifying a cluster's nature [68]. The silhouette score ranges from -1 to 1 , with a higher score indicating a better separation from other clusters. In this study, the average silhouette value of all clusters is 0.9265 , which indicates that the clusters are highly homogeneous, i.e., articles appear to be written with little relation to other studies. Work in this area appears fragmented, limited in scope, and sometimes repetitive, tending not to be undertaken as development or extension of previous work. 


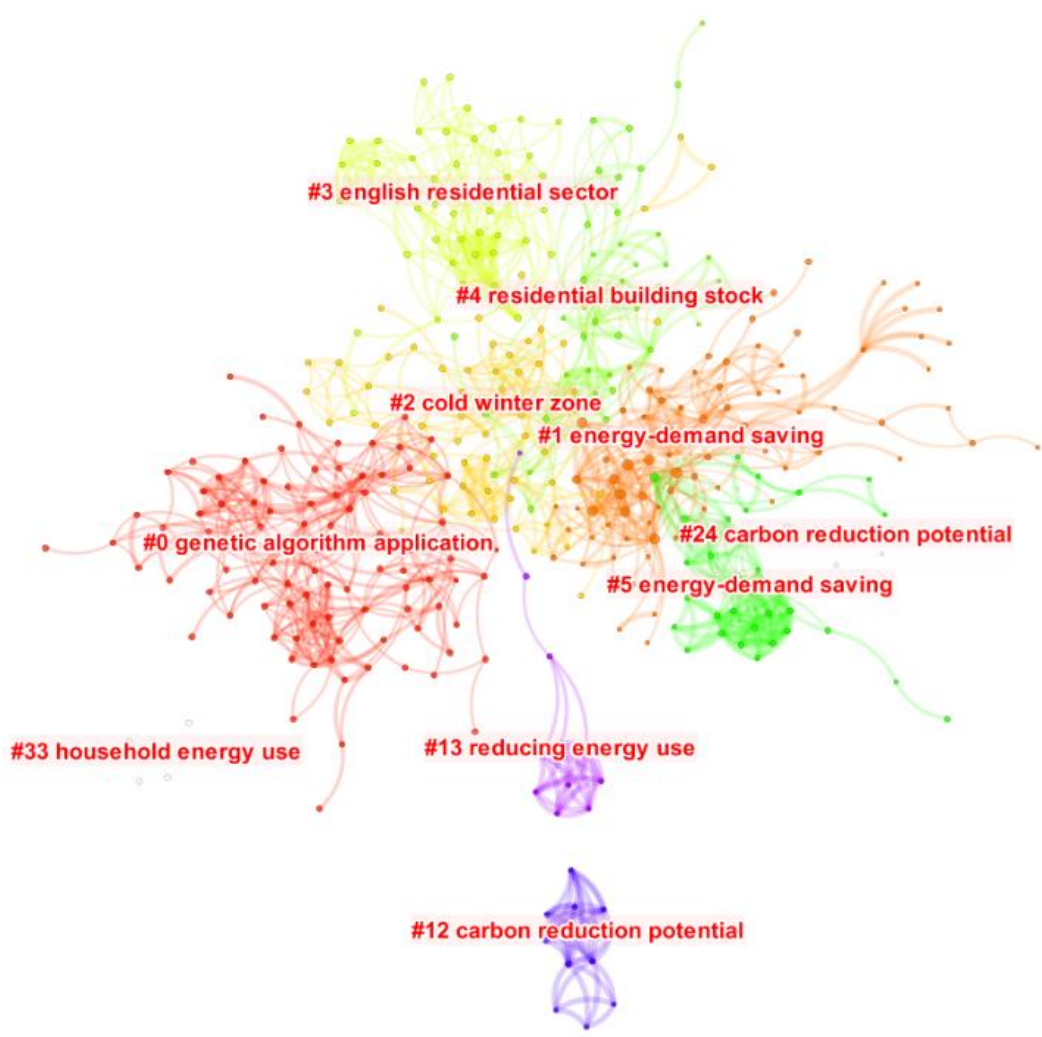

Figure 5. The cluster of co-citation analysis.

In this paper, the co-citation analysis of studies contains 107 clusters of different sizes, which together present the landscape of knowledge development in the field of retrofitting residential buildings. Detailed information of the first six clusters, which contain 337 nodes accounting for about $47 \%$ of the total nodes, is provided in Table 2.

Table 2. Main clusters and their content focus.

\begin{tabular}{ccccc}
\hline Clusters & Size & Silhouette & Mean Year & The Main Focus of the Cluster \\
\hline 0 & 94 & 0.91 & 2015 & genetic algorithm application, data-driven approach \\
1 & 85 & 0.903 & 2010 & energy-demand saving, genetic algorithm application \\
2 & 61 & 0.943 & 2014 & cold winter zone, hot summer, low carbon heating \\
3 & 51 & 0.962 & 2012 & English residential sector, energy efficiency investment \\
4 & 46 & 0.858 & 2011 & residential building stock, cost-benefit analysis \\
\hline
\end{tabular}

Cluster 0 has 94 cited references, with an average publication year of 2015. Generic algorithms are based on the Darwinian "natural selection" concept to generate optimal solutions [69]. This cluster's first two highly cited references are Noris, Adamkiewicz [70] and Asadi, Silva [71]. Noris, Adamkiewicz [70] retrofitted 16 apartments for low-income residents in three buildings, using different approaches to minimising energy usage while enhancing IEQ. Their work's outcomes indicate general improvements in comfort conditions, carbon dioxide concentrations, bathroom humidity, acetaldehyde, particle matter mass $(2.5 \mu \mathrm{m})$, and voltage organic compounds. Asadi, Silva [71] proposed a multi-objective optimisation model using artificial neural networks and generic algorithms to evaluate options in a building retrofitting project. Their work starts with the single optimisation of objective functions, focusing on a school building's performance and characteristics as a case study, including retrofit cost, energy usage, and thermal discomfort hours. After that, the proposed model was used to investigate the interaction between these conflicting objectives and evaluate their trade-offs. 
Cluster 1 has 85 cited references, published in 2010, on average, with a research focus on energy-demand saving. One of the most cited studies in this cluster is Ma, Cooper [72]. Their research proposes a systemic method to properly select and identify the best retrofit possibilities for existing buildings. They discussed the building retrofit issues that impact retrofit decision-making. Additionally, major retrofitting activities, including energy auditing, quantification of energy benefits, building performance evaluation, economic analysis, risk measurement, measurement, and energy savings verification, are briefly reviewed in their work.

Cluster 2 has 61 cited references, with an average publication year of 2014, which probes aspects of the cold winter zone. This cluster's first two highly cited references are Kavgic, Mavrogianni [73] and Ballarini, Corgnati [74]. Kavgic, Mavrogianni [73] critically evaluated the existing bottom-up building physics-based residential energy models and identified the next generation of coupled energy-health bottom-up building stock models. Bottom-up models are built from information on a hierarchy of disaggregated elements combined according to assessments that influence energy consumption. Nic and Mark [75] argue that these models are also accepted as an approach to identify the most cost-effective alternatives to achieve given carbon decline targets using the best available technologies and processes. Ballarini, Corgnati [74] proposed a method for the identification of 18 reference buildings among different categories drawn from European residential building stock from which they developed a harmonized structure focusing on potential energy savings and diminished carbon dioxide emissions.

On average, cluster 3 has 61 cited references, published in 2012, with the English residential sector as the research subject. This cluster's first two highly cited references are Nair, Gustavsson [76] and Dowson, Poole [77]. Nair, Gustavsson [76] evaluated the factors that influence the selection of energy efficiency measures to reduce energy consumption using data collected from 3000 detached house owners in Sweden. They argue that personal attributes, including education, income, age, and contextual factors, such as thermal discomfort, house age, perceived energy cost, and past investment, affect homeowners preferences for a specific energy efficiency measure. Dowson, Poole [77] investigated the existing UK housing stock's thermal performance along with the challenges of retrofitting these to reduce energy usage and carbon dioxide emissions. They found that there is a strong relationship between the age of dwellings and their thermal performance. They also argue that the high capital cost of some retrofitting strategies, such as new generation of double-glazed windows, and wall insulation, as well as their long financial payback period are the major barriers.

Cluster 4 has 46 cited references, with an average publication year of 2011. It probes residential building stock and cost-benefit analysis. This cluster's first two highly cited references are Sunikka-Blank and Galvin [78] and Mata, Sasic Kalagasidis [79]. SunikkaBlank and Galvin [78] compared the energy performance ratings of 3400 German homes for space and water heating, using existing data on actual measured usage. They argued that there is a gap between energy performance and the measured energy consumption. They also concluded that building users generally behave more economically in homes that experience greater thermal discomfort issues after retrofitting. Mata, Sasic Kalagasidis [79] evaluated the energy consumption and carbon dioxide emissions of 1400 Swedish residential buildings. They used bottom-up modeling technology to evaluate 12 energy-saving measures (ESMs). They argued that the application of selected ESMs could diminish energy demand by $53 \%$, and the level of carbon dioxide by $63 \%$. Some measures, such as heat recovery, decreased the indoor temperature, while upgrading the U-values of the building envelope and the windows returned the maximum impact.

\subsection{Direct Citation Analysis}

Generally, three methods are used to explore the citation correlation between sources: direct citation, bibliographic coupling, and co-citation analysis [60]. The direct citation method is used to explore correlations between two publications where one publication 
cites the other. The bibliographic coupling method is used to identify correlations between publications that cite the same publication. The co-citation method is used to explore correlations between publications that are cited by the same publication. Waltman and Eck [80] argue that co-citation and bibliographic coupling correlations are indirect correlations, and therefore, provide less accurate data on the relatedness of publications than direct citation correlations. Additionally, Shibata, Kajikawa [81] claim that direct citation correlation is the best and quickest method to identify emerging research domains to compare co-citation and bibliographic coupling correlations. Nonetheless, direct citation analysis has limitations. For example, some publications might not have any direct citation correlations with other items, and therefore, cannot be assigned to a source.

As can be seen from Figure 6, the publication 'Energy and Buildings' is the premier source of reference material used by subsequent publications on residential retrofitting. 'Journal of Cleaner Production, 'Energy Policy', 'Sustainable Cities and Society', Applied Energy', and 'Energy' are essential additional sources of research citation. The size of nodes represents the citation of publications to compare with others. The bigger the node size, the more citation received. The thickness of lines is based on the number of citations between the two nudes.

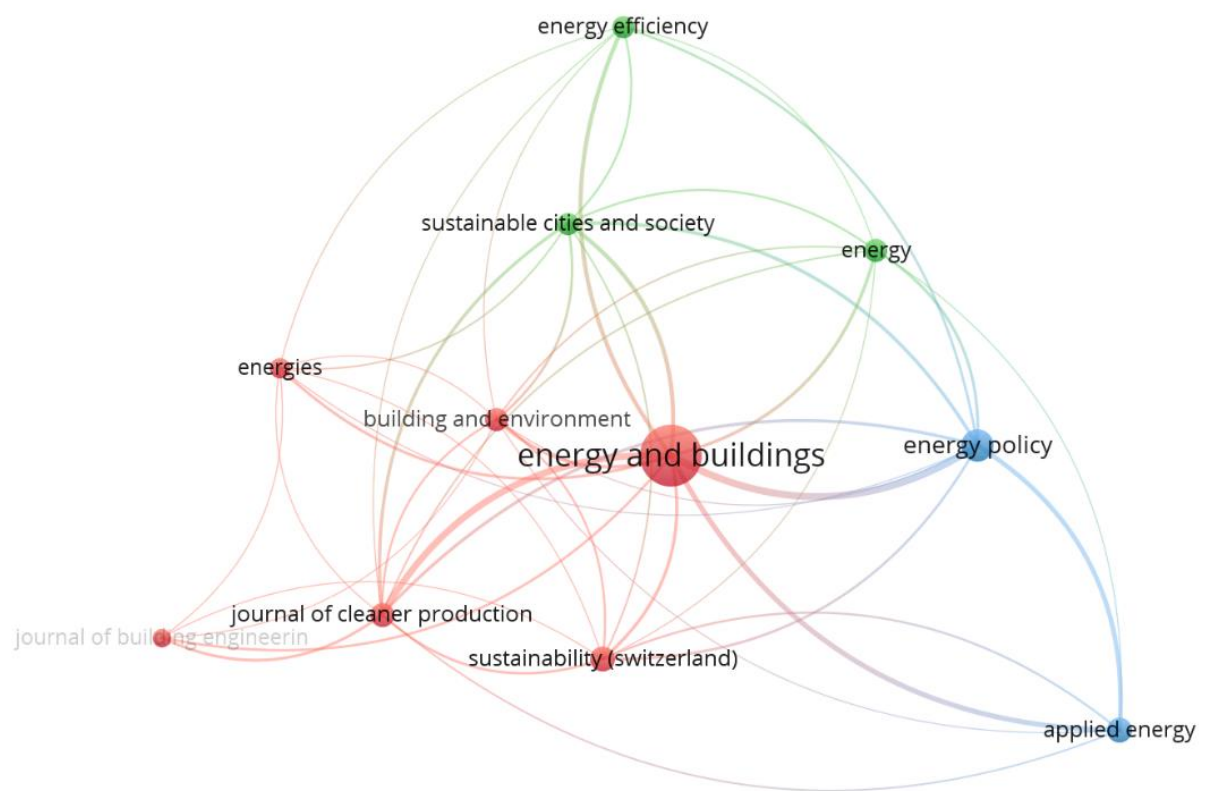

Figure 6. Direct citation analysis linkages between publications.

\section{Findings}

Sustainability, climate change, and in particular the impact of human-induced global warming, is seen by many as the crisis of our times. There is a global collective call for nations to reduce greenhouse gas emissions, and the further challenge faced is one of how this can possibly be achieved. The main culprit is $\mathrm{CO}_{2}$ emissions, and the most direct route to $\mathrm{CO}_{2}$ reductions is the transition from fossil fuels (gas and petroleum) to so-called renewable energies (solar, wind, biofuels, wave, etc.). Less appreciated outside of the building community is that it is the built environment that consumes the vast bulk of total world energy usage. Moreover, building activity itself is the main contributor to other features of the world's poor sustainability outcomes: high waste, resource degradation, ground and air pollution, environmental damage, while the building industry itself harbours notoriously poor social equity practices; particularly in developing nations.

Although this is generally appreciated, the obvious fact is that if poor sustainability outcomes along with high energy usage and high $\mathrm{CO}_{2}$ emissions are to be addressed, attention must not only focus on the built environment per se, not only on the residential 
sector, which constitutes the bulk of construction activity but on the retrofitting of the current residential building stock. To be clear, running and maintaining the world's existing residential buildings is by far the greatest source of energy consumption, waste production and greenhouse gas generation.

Interestingly, the first finding of this study is that research on building retrofitting hardly touches on this core fact. That is the holistic potential of building retrofitting as a strategic means to address 'global warming' goes largely undiscussed. This ought to be explored in greater depth.

What we do see, however, is a new and growing interest in the theme of retrofitting. Prior to 2011, publications on retrofitting averaged only a couple per year. However, over the last decade, publications have skyrocketed. Indeed, last year (2020), publications reached a current peak of 96 papers. Why this recent fast-growing interest? A qualitative analysis of the papers reveals that interest in retrofitting is essentially directed by the perceived need to find ways to offset rising energy costs, primarily in water heating and ambient residential cooling and heating. Consequently, the bulk of papers deal with evaluations of alternative systems that reduce energy costs while maintaining similar service delivery outcomes. It also appears that these elements are the focus because homeowners and occupiers drive the retrofit agenda in their effort to curb energy costs. Their awareness of rising energy costs is constrained by what is obvious to them: water heating and HVAC systems.

This is an important finding as much more can be done to improve the thermal and energy performance of residential buildings than simply replacing water heaters and aircon systems. This study reveals some of these other directions; but the scarcity of breadth of alternate topics, combined with the scant numbers of papers on these alternate topics, highlights the narrowness of focus on the recent burst of retrofitting publications seen this last decade. Candidate areas for further study, though touched on by the odd paper but in need of deeper examination, include ventilation, insulation, building envelopes, materials, air quality, weather protection and occupant behaviour.

Moreover, there are clearly many additional themes that would be worthwhile but have not evidently been pursued in residential retrofit. Given the continuing interest in climate change and the unlikeliness that rising energy costs and global warming concerns will abate anytime soon, these themes can be expected to be taken up presently. Indeed, we would commend interested researchers to champion any of the following areas to improve our understanding of how best to conduct residential retrofitting. Suggested emerging themes are:

- Government policy as it relates to retrofitting

- $\quad$ Retrofitting market and supply chains

- Comparisons in practice across national boundaries

- Comparisons across residential building types

- Comparisons across types and modes of retrofitting intervention

- Comparisons of proprietary system performance benchmarks

- Cost-benefit analysis of before and after retrofitting scenarios

- Examination of conduciveness on initial residential designs to absorb retrofits

- Materials, integrated systems and real-time performance measuring

- Assessment of existing energy rating systems to absorb and rate retrofitting

- Occupant values and preferences regarding optimisation of outcomes

- Impact of retrofitting strategies to mitigate effects of climate change

\section{Conclusions}

Climate change and global warming have been identified as the crisis of our times. The consensus appears to be that carbon emissions must be reduced drastically and soon if catastrophe is averted. Much of the focus regarding efforts to secure a sustainable future neglect recognising that it is the built environment and the building industry that contributes the most to pollution, waste, landfill, resource depletion and, above all, energy 
consumption and carbon emissions. Moreover, to the extent that the harm done by the built environment is acknowledged, most research has focused on the role played by commercial and industrial buildings. These are typically showcased as 'green buildings', all part of corporate efforts to promote 'virtue signalling' and 'social responsibility'. However, the bulk of the built environment is not commercial but residential. Moreover, while transitioning to more sustainable construction in new residential builds is both necessary and commendable, the inescapable reality is that the existing residential building stock continues to pose the greatest sustainability challenge. Specifically, the existing stock of residential buildings and their proclivity to consume huge amounts of energy and generate vast volumes of $\mathrm{CO}_{2}$ pose the most significant single barrier to the sustainability goals of the world's nations.

Short of tearing down existing buildings, which of course is no solution at all, what then is to be done regarding the existing stock of residential buildings worldwide. The answer is to retrofit them and do so with the view of reducing energy consumption, either through efficiency gains or waste minimisation. There is significant research available in this realm and some critical publication outlets that support the mission. However, to date, the extent, scope and quality of that research has not been mapped, documented or described. This study delivers on that deficit. It presents a scientometric analysis of the research so far conducted in retrofitting residential buildings. It finds that the research theme has only recently gained any significant traction, with a significant publication surge evident from only 2017. Moreover, it reveals that while there are many potential research themes-from occupant behaviour to energy performance certification-the bulk of research is very circumspect in scope, being primarily limited to studies exploring trade-offs between energy usage reduction strategies thermal comfort. Finally, this study notes that there are only a limited number of academics working in this area, with most citations arising from only a few journals, of which 'Energy and Buildings' stand out as premiere.

This study has its limitations; specifically, it is only exploratory and general in nature and scope. More detailed analysis and appraisal of study findings in this field would be a logical next step to be undertaken.

Author Contributions: M.A. was responsible for literature review, data collection, software use, methodology, critical analysis, visualization and writing. I.M. was responsible for conceptualization, methodology, critical analysis and writing. M.B.L. was responsible for identifying the importance and relevance of this field of research. All authors have read and agreed to the published version of the manuscript.

Funding: This research received no external funding.

Institutional Review Board Statement: Not applicable.

Informed Consent Statement: Not applicable.

Conflicts of Interest: The authors declare that there is no conflict of interest.

\section{References}

1. McKibben, W. Winning Slowly Is the Same as Losing. Rolling Stone, 2017. Available online: https:/ / www.rollingstone.com/ politics/news/bill-mckibben-winning-slowly-is-the-same-as-losing-w512967 (accessed on 5 March 2021).

2. Ortiz, O.; Castells, F.; Sonnemann, G. Sustainability in the construction industry: A review of recent developments based on LCA. Constr. Build. Mater. 2009, 23, 28-39. [CrossRef]

3. Martek, I.; Hosseini, M.R.; Shrestha, A.; Zavadskas, E.K.; Seaton, S. The Sustainability Narrative in Contemporary Architecture: Falling Short of Building a Sustainable Future. Sustainability 2018, 10, 981. [CrossRef]

4. Masanauskas, J. Melbourne's Continuing Population Boom Means Another 720,000 Homes Will Be Needed by 2031; Herals Sun: Melbourne, VIC, Australia, 2014.

5. Australian Sustainable Built Environment Council. A National Framework for Residential Ratings: Discussion Paper. 2016; ASBEC: Darlinghurst, NSW, Australia, 2010.

6. Aye, L.; Hes, D. Green Building Rating System Scores for Building Reuse. J. Green Build. 2012, 7, 105-112. [CrossRef] 
7. Building Energy Efficiency Task Group. Building Energy Rating Schemes: Assessing Issues and Impacts; International Partnership for Energy Efficiency Cooperation: Paris, France, 2014.

8. Jackson, S. A summary of urban assessment tools for application in Australia. In Environment Design Guide; Australian Institute of Architects: Potts Point, NSW, Australia, 2016.

9. Doan, D.T. A critical compariosn of green building rating systems. Build. Environ. 2017, 123, 243-260. [CrossRef]

10. Green Building Council of Australia. Available online: https://new.gbca.org.au/ (accessed on 8 April 2021).

11. Rashid, M.; Spreckelmeyer, K.; Angrisano, N. Green buildings: Environmental awareness and corporate image. J. Corp. Real Estate 2012, 14, 21-49. [CrossRef]

12. Tam, V.W.Y.; Zeng, S.X. Sustainable Performance Indicators for Australian Residential Buildings. J. Leg. Aff. Disput. Resolut. Eng. Constr. 2013, 5, 168-179. [CrossRef]

13. Harvey, L.D.D. Reducing energy use in the buildings sector: Measures, costs, and examples. Energy Effic. 2009, 2, 139-163. [CrossRef]

14. Hughes, P.J.; Shonder, J.A. The Evaluation of A 4000-Home Geothermal Heat Pump Retrofit at Fort Polk, Louisiana: Final Report. OSTI 1998. [CrossRef]

15. Bell, M.; Lowe, R. Energy efficient modernisation of housing: A UK case study. Energy Build. 2000, 32, 267-280. [CrossRef]

16. Viridén + Partner. 2020. Available online: https://www.viriden-partner.ch/plus-nullenergiehaeuser (accessed on 9 April 2021).

17. Francisco, P.W.; Palmiter, L.; Davis, B. Modeling the thermal distribution efficiency of ducts: Comparisons to measured results. Energy Build. 1998, 28, 287-297. [CrossRef]

18. Voss, K. Solar energy in building renovation-Results and experience of international demonstration buildings. Energy Build. 2000, 32, 291-302. [CrossRef]

19. Chen, S.; Guan, J.; Levine, M.D.; Haiying, L.; Yowargana, P. Evaluation on Retrofit of One Existing Residential Building in North China: Energy Saving, Environmental and Economic Benefits. Procedia Eng. 2015, 121, 3-10. [CrossRef]

20. Friedman, C.; Becker, N.; Erell, E. Retrofitting residential building envelopes for energy efficiency: Motivations of individual homeowners in Israel. J. Environ. Plan. Manag. 2017, 61, 1805-1827. [CrossRef]

21. Aghili, N.; Amirkhani, M. SEM-PLS Approach to Green Building. Encyclopedia 2021, 1, 472-481. [CrossRef]

22. Amirkhani, M.; Garcia-Hansen, V.; Isoardi, G.; Allan, A. Innovative window design strategy to reduce negative lighting interventions in office buildings. Energy Build. 2018, 179, 253-263. [CrossRef]

23. Amirkhani, M. Innovative Integrated Window Design with Electric Lighting Design System to Reduce Lighting Intervention in Office Buildings; Queensland University of Technology: Brisbane, QLD, Australia, 2018.

24. Eom, J. China's building energy demand: Long-term implications from a detailed assessment. Energy 2012, 46, 405-419. [CrossRef]

25. OECD. Cooperation, O.F.E. and Development, Energy Balances of Non-OECD Countries 2015; OECD: Paris, France, 2015.

26. Union European. EU Energy in Figures: Statistical Pocketbook 2018; Publications Office of the European Union: Luxembourg, 2018.

27. Eichhammer, W.; Fleiter, T.; Schlomann, B.; Faberi, S.; Fioretto, M.; Piccioni, N.; Lechtenböhmer, S.; Schüring, A.; Resch, G. Study on the Energy Savings Potentials in EU Member States, Candidate Countries and EEA Countries: Final Report for the European Commission Directorate-General Energy and Transport 2009; EU Energy Poverty Observatory: Brussels, Belgium, 2009.

28. Paiho, S.; Seppä, I.P.; Jimenez, C. An energetic analysis of a multifunctional façade system for energy efficient retrofitting of residential buildings in cold climates of Finland and Russia. Sustain. Cities Soc. 2015, 15, 75-85. [CrossRef]

29. AE Smith. City of Melbourne, 1200 Buildings: Melbourne Report Survey; AE Smith: Brisbane, QLD, Australia, 2015.

30. Shah, S. Sustainable Refurbishment; Wiley-Blackwell: Hoboken, NJ, USA, 2012.

31. Zou, P.X. Retrofitting public buildings for energy and water efficiency. In Sustainable Built Environment; National Research Centre: Boulder, CO, USA, 2016.

32. Volt, J.; Fabbri, M.; Groote, M. Understanding Potential User Needs. In A Survey Analysis of the Markets for Individual Building Renovation Roadmaps in Bulgaria, Poland and Portugal; iBRoad: Europe, 2018; p. 106.

33. Web of Science. 2020. Available online: https://clarivate.com/webofsciencegroup/solutions/web-of-science/ (accessed on 2 February 2021).

34. Scopus. 2020. Available online: https://www.elsevier.com/solutions/scopus?dgcid=RN_AGCM_Sourced_300005030 (accessed on 2 February 2021).

35. Li, J.; Goerlandt, F.; Reniers, G. An overview of scientometric mapping for the safety science community: Methods, tools, and framework. Saf. Sci. 2021, 134, 105093. [CrossRef]

36. Chaomei, C. Science Mapping: A Systematic Review of the Literature. J. Data Inf. Sci. 2017, 2, 1-40.

37. Small, H.; Rorvig, M.E.; Lunin, L.F. Visualizing science by citation mapping. J. Am. Soc. Inf. Sci. 1999, 50, 799-813. [CrossRef]

38. Cobo, M.J.; Lopez-Herrera, A.G.; Herrera-Viedma, E.; Herrera, F. An approach for detecting, quantifying, and visualizing the evolution of a research field: A practical application to the Fuzzy Sets Theory field. J. Inf. 2011, 5, 146-166. [CrossRef]

39. Merschbrock, C.; Hosseini, M.R.; Martek, I.; Arashpour, M.; Mignone, G. Collaborative Role of Sociotechnical Components in BIM-Based Construction Networks in Two Hospitals. J. Manag. Eng. 2018, 34, 05018006. [CrossRef]

40. Cobo, M.; López-Herrera, A.; Herrera-Viedma, E.; Herrera, F. Science mapping software tools: Review, analysis, and cooperative study among tools. J. Am. Soc. Inf. Sci. Technol. 2011, 62, 1382-1402. [CrossRef]

41. Pritchard, A. Statistical bibliography or bibliometrics. J. Doc. 1969, 25, 348-349. 
42. Henderson, M.; Shurville, S.; Fernstrom, K. The Quantitative Crunch: The Impact of Bibliometric Research Quality Assessment Exercises on Academic Development at Small Conferences. Campus-Wide Inf. Syst. 2009, 26, 149-167. [CrossRef]

43. Antonio-Rafael, R.-R.; José, R.-N. Changes in the Intellectual Structure of Strategic Management Research: A Bibliometric Study of the "Strategic Management Journal", 1980-2000. Strateg. Manag. J. 2004, 25, 981-1004.

44. Broadus, R.N. Toward a definition of "bibliometrics". Scientometrics 1987, 12, 373-379. [CrossRef]

45. Martín-Martín, A.; Malea, E.O.; López-Cózar, E.D. A novel method for depicting academic disciplines through Google Scholar Citations: The case of Bibliometrics. Scientometrics 2017, 114, 1251-1273. [CrossRef]

46. Nalimov, V.V.; Mulchenko, Z.M. Measurement of Science. Study of the Development of Science as an Information Process; National Technical Information Service: Springfield, VA, USA, 1971.

47. Hood, W.W.; Wilson, C.S. The Literature of Bibliometrics, Scientometrics, and Informetrics. Scientometrics 2001, 52, $291-314$. [CrossRef]

48. Tague-Sutcliffe, J. An introduction to informetrics. Inf. Process. Manag. 1992, 28, 1-3. [CrossRef]

49. Morris, S.A.; Martens, B.V.D.V. Mapping research specialties. Annu. Rev. Inf. Sci. Technol. 2009, 42, 213-295. [CrossRef]

50. Nacke, O.I. Ein neuer Name für eine neue Disziplin. Nachr. Dokum. 1979, 30, 219.

51. Bar-Ilan, J. Beyond Citations: Scholars' Visibility on the Social Web; Cornell University: Ithaca, NY, USA, 2012.

52. Zhao, X. A scientometric review of global BIM research: Analysis and visualization. Autom. Constr. 2017, 80, 37-47. [CrossRef]

53. He, Q.; Wang, G.; Luo, L.; Shi, Q.; Xie, J.; Meng, X. Mapping the managerial areas of Building Information Modeling (BIM) using scientometric analysis. Int. J. Proj. Manag. 2017, 35, 670-685. [CrossRef]

54. Ren, R.; Hu, W.; Dong, J.; Sun, B.; Chen, Y.; Chen, Z. A Systematic Literature Review of Green and Sustainable Logistics: Bibliometric Analysis, Research Trend and Knowledge Taxonomy. Int. J. Environ. Res. Public Health 2019, 17, 261. [CrossRef] [PubMed]

55. Wang, Z.-Y.; Li, G.; Li, C.-Y.; Li, A. Research on the semantic-based co-word analysis. Scientometrics 2011, 90, 855-875. [CrossRef]

56. Leung, X.Y.; Sun, J.; Bai, B. Bibliometrics of social media research: A co-citation and co-word analysis. Int. J. Hosp. Manag. 2017, 66, 35-45. [CrossRef]

57. Small, H. Co-citation in the scientific literature: A new measure of the relationship between two documents. J. Am. Soc. Inf. Sci. 1973, 24, 265-269. [CrossRef]

58. Shiau, W.-L.; Dwivedi, Y.K.; Yang, H.S. Co-citation and cluster analyses of extant literature on social networks. Int. J. Inf. Manag. 2017, 37, 390-399. [CrossRef]

59. Yang, S.; Wang, F. Visualizing information science: Author direct citation analysis in China and around the world. J. Inf. 2015, 9, 208-225. [CrossRef]

60. Van Eck, N.J.; Waltman, L. Citation-based clustering of publications using CitNetExplorer and VOSviewer. Scientometrics 2017, 111, 1053-1070. [CrossRef] [PubMed]

61. Chen, C. CiteSpace II: Detecting and visualizing emerging trends and transient patterns in scientific literature. J. Am. Soc. Inf. Sci. Technol. 2006, 57, 359-377. [CrossRef]

62. Chen, C.; Ibekwe-SanJuan, F.; Hou, J. The Structure and Dynamics of Co-Citation Clusters: A Multiple-Perspective Co-Citation Analysis. J. Am. Soc. Inf. Sci. Technol. 2010, 61, 1386-1409. [CrossRef]

63. Vliet, G.C. Retrofitting of an Apartment Building for Solar Heating, Cooling and Hot Water; Regulatory Processes of the US Department of Energy: Dearborn, MI, USA, 1979; pp. 387-401.

64. Ding, Y.; Rousseau, R.; Wolfram, D. (Eds.) Measuring Scholarly Impact Methods and Practice, 1st ed.; Springer International Publishing: Cham, Switzerland, 2014.

65. Zhang, P.; Liu, Y.; Yu, F.-X.; Wu, G.-W.; Li, M.-Y.; Wang, Z.; Ding, H.-Y.; Wang, L.-X.; Zhao, K.-X.; Zhang, Z.-Y.; et al. Hierarchical integrated processing of reward-related regions in obese males: A graph-theoretical-based study. Appetite 2021, 159, 105055. [CrossRef] [PubMed]

66. Opsahl, T.; Agneessens, F.; Skvoretz, J. Node centrality in weighted networks: Generalizing degree and shortest paths. Soc. Netw. 2010, 32, 245-251. [CrossRef]

67. Newman, M.E.J. Modularity and community structure in networks. Proc. Natl. Acad. Sci. USA 2006, 103, 8577-8582. [CrossRef]

68. Rousseeuw, P.J. Silhouettes: A graphical aid to the interpretation and validation of cluster analysis. J. Comput. Appl. Math. 1987, 20, 53-65. [CrossRef]

69. Deb, K. A fast and elitist multiobjective genetic algorithm: NSGA-II. IEEE Trans. Evol. Comput. 2002, 6, 182-197. [CrossRef]

70. Noris, F.; Adamkiewicz, G.; Delp, W.W.; Hotchi, T.; Russell, M.; Singer, B.C.; Spears, M.; Vermeer, K.; Fisk, W.J. Indoor environmental quality benefits of apartment energy retrofits. Build. Environ. 2013, 68, 170-178. [CrossRef]

71. Asadi, E.; da Silva, M.C.G.; Antunes, C.H.; Dias, L.; Glicksman, L. Multi-objective optimization for building retrofit: A model using genetic algorithm and artificial neural network and an application. Energy Build. 2014, 81, 444-456. [CrossRef]

72. Ma, Z.; Cooper, P.; Daly, D.; Ledo, L. Existing building retrofits: Methodology and state-of-the-art. Energy Build. 2012, 55, 889-902. [CrossRef]

73. Kavgic, M.; Mavrogianni, A.; Mumovic, D.; Summerfield, A.; Stevanovic, Z.; Djurovic-Petrovic, M. A review of bottom-up building stock models for energy consumption in the residential sector. Build. Environ. 2010, 45, 1683-1697. [CrossRef]

74. Ballarini, I.; Corgnati, S.P.; Corrado, V. Use of reference buildings to assess the energy saving potentials of the residential building stock: The experience of TABULA project. Energy Policy 2014, 68, 273-284. [CrossRef] 
75. Nic, R.; Mark, J. Combining Top-Down and Bottom-Up Approaches To Energy-Economy Modeling Using Discrete Choice Methods. Energy J. Camb. Mass. 2005, 26, 83-106.

76. Nair, G.; Gustavsson, L.; Mahapatra, K. Factors influencing energy efficiency investments in existing Swedish residential buildings. Energy Policy 2010, 38, 2956-2963. [CrossRef]

77. Dowson, M.; Poole, A.; Harrison, D.; Susman, G. Domestic UK retrofit challenge: Barriers, incentives and current performance leading into the Green Deal. Energy Policy 2012, 50, 294-305. [CrossRef]

78. Sunikka-Blank, M.; Galvin, R. Introducing the prebound effect: The gap between performance and actual energy consumption. Build. Res. Inf. 2012, 40, 260-273. [CrossRef]

79. Mata, É.; Kalagasidis, A.S.; Johnsson, F. Energy usage and technical potential for energy saving measures in the Swedish residential building stock. Energy Policy 2013, 55, 404-414. [CrossRef]

80. Waltman, L.; Eck, N.J. A new methodology for constructing a publication-level classification system of science. J. Am. Soc. Inf. Sci. Technol. 2012, 63, 2378-2392. [CrossRef]

81. Shibata, N.; Kajikawa, Y.; Takeda, Y.; Matsushima, K. Detecting emerging research fronts based on topological measures in citation networks of scientific publications. Technovation 2008, 28, 758-775. [CrossRef] 